\title{
ENFERMEDAD PULMONAR POR Mycobacterium intracellulare EN UNA PACIENTE INMUNOCOMPETENTE: REPORTE DE UN CASO EN EL PERÚ
}

\author{
Roberto Alfonso Accinelli (1) 1,2,3,a, Alfredo Camposano (1) 1,2,b \\ 1 Instituto de Investigaciones de la Altura, Universidad Peruana Cayetano Heredia, Lima, Perú. \\ 2 Facultad de Medicina, Universidad Peruana Cayetano Heredia, Lima, Perú. \\ ${ }^{3}$ Hospital Cayetano Heredia, Lima, Perú. \\ a Médico neumólogo; maestro en salud pública; ${ }^{\mathrm{b}}$ Estudiante de medicina
}

\section{RESUMEN}

Presentamos una paciente inmunocompetente cuya enfermedad comenzó a los 49 años con tos, seguida de esputo purulento y hemoptoico, por lo que se diagnosticó bronquiectasias. Tres años después, luego de hemoptisis, le practicaron segmentectomía medial del lóbulo medio y quedó asintomática por meses. $\mathrm{Al}$ encontrarse tuberculosis en el informe de patología fue tratada con $4 \mathrm{HREZ2} \mathrm{R}_{2} \mathrm{H}_{2}$. Cinco años después su BK fue $2+$ recibiendo un nuevo esquema de $4 \mathrm{HREZ}_{2} \mathrm{R}_{2} \mathrm{H}_{2}$, con lo que no logro negativizar declarándose el fracaso al tratamiento. Al hallar en la genotipificación de su cultivo Mycobacterium intracellulare, la paciente recibió azitromicina, moxifloxacina y etambutol, hubo mejoría, pero abandonó el tratamiento a los ocho meses; lo reinició 18 meses después, junto con tratamiento para la depresión y el reflujo gastroesofágico. Al mes la paciente estuvo asintomática, pero hizo reacción dérmica a la moxifloxacina y se la reemplazó por amikacina. Salió de alta y al año estuvo curada, a los 64 años de edad.

Palabras clave: Mycobacterium tuberculosis; Complejo Mycobacterium avium; Reflujo Gastroesofágico; Micobacterias no Tuberculosas; Depresión. (fuente: DeCS BIREME).

\section{PULMONARY DISEASE BY mycobacterium intracellulare IN AN IMMUNOCOMPETENT PATIENT: REPORT OF A CASE IN PERU}

\begin{abstract}
We present the case of an immunocompetent patient whose illness began at age 49 with a cough, followed by purulent and hemoptoic sputum; bronchiectasis was diagnosed. Three years later, after hemoptysis, she underwent medial segmentectomy of the middle lobe and was asymptomatic for months. When tuberculosis was found in the pathology report, she was treated with $4 \mathrm{HREZ} 2 \mathrm{R}_{2} \mathrm{H}_{2}$. Five years later her BK was $2+$, thus receiving a new scheme of $4 \mathrm{HREZ} 2 \mathrm{R}_{2} \mathrm{H}_{2}$, which did not succeed in obtaining negative results and the treatment was declared as a failure. After genotyping her Mycobacterium intracellulare culture, the patient received azithromycin, moxifloxacin and ethambutol. There was improvement, but she abandoned the treatment at 8 months; she restarted it 18 months later, along with treatment for depression and gastroesophageal reflux. After one month the patient was asymptomatic, but she had a dermal reaction to moxifloxacin which was replaced with amikacin. One year later, she was cured and discharged, at the age of 64 .
\end{abstract}

Camposano: Accinelli RA, pulmonar por Mycobacterium intracellulare en una paciente inmunocompetente: reporte de un caso en el Perú. Rev Peru Med Exp Salud Publica. 2020;37(2):361-6. doi: https://doi. org/10.17843/rpmesp.2020.372.4632

Correspondencia: Roberto Alfonso Accinelli, Roberto.accinelli@upch.pe

Keywords: Mycobacterium tuberculosis; Mycobacterium avium Complex; Gastroesophageal Reflux; Nontuberculous Mycobacteria; Depression (source: MeSH NLM).

\section{INTRODUCCIÓN}

Mycobacterium intracellulare, Mycobacterium avium y unas decenas más de especies forman el complejo Mycobacterium-avium (MAC) ${ }^{(1)}$. Con el advenimiento de la epidemia del sida y la mejora de la tecnología se ha hecho más común su diagnóstico ${ }^{(2)}$. En el Perú se han reportado seis casos en inmunocomprometidos por el virus de la inmunodeficiencia adquirida (VIH). El objetivo del reporte es presentar el primer caso documentado de enfermedad pulmonar por Mycobacterium intracellulare en una paciente inmunocompetente. 


\section{REPORTE DE CASO}

Mujer de 49 años que inició su enfermedad con tos seca, que dos años después se hizo productiva, llegando a tener hemoptisis de 120 mililitros. La paciente era VIH negativo, no recibió tratamiento con inmunosupresores ni esteroides. Tampoco tenía antecedentes de enfermedad del tejido conectivo, diabetes mellitus, HTLV-1, cáncer, ni otra dolencia asociada con depresión inmunitaria. La descripción de las manifestaciones clínicas y del tratamiento recibido durante todos los años se muestran en la Figura 1.

\begin{tabular}{|c|}
\hline Síntoma inicial: tos seca. \\
\hline $\begin{array}{l}\text { Tos productiva, hemoptisis, bronquiectasias } \\
\text { localizadas en segmento medial del lóbulo }\end{array}$ \\
\hline $\begin{array}{l}\text { Presencia de granulomas en pieza quirúrgica } \rightarrow \text { se } \\
\text { diagnostica TB. }\end{array}$ \\
\hline Se identificó Mycobacterium intracellulare. \\
\hline $\begin{array}{l}\text { Tos exigente, esputo purulento y hemoptoico. } \\
\text { BAAR }(2+) \text { en esputo. }\end{array}$ \\
\hline
\end{tabular}

La paciente acude a consulta. Se identificó Mycobacterium intracellulare. Además, se diagnostica ERGE y depresión por especialista.

18 meses después de abandonar tratamiento, tos empeoró, y se hizo productiva. Perdió $3 \mathrm{~kg}$ de peso. Presentó lesiones de actividad en tomografía espiral multicorte.

1 año de tratamiento. Completamente asintomática. Ganó $6 \mathrm{~kg}$ de peso, exámenes de esputo negativos (directos y cultivos). Tomografía espiral multicorte: desaparición de signos de actividad de enfermedad pulmonar por micobacteria no tuberculosa (EPMNT).
En 2007, la paciente persistía con tos productiva, se le encuentran bronquiectasias localizadas en el segmento medial del lóbulo medio derecho (Figura 2A, 2B, 2C), por lo que se le resecó dicho segmento. La paciente quedó asintomática por varios meses. En 2008, en vista del hallazgo de granulomas en la pieza quirúrgica resecada, se diagnosticó tuberculosis y recibió el esquema $2 \mathrm{RHEZ}_{2} \mathrm{R}_{2} \mathrm{H}_{2}$ (dos meses rifampicina, isoniacida, pirazinamida y etambutol diario; y cuatro meses rifampicina e isoniacida, dos veces por semana). Cinco años después, la paciente presentó tos persistente, esputo purulento y hemoptoico. Se encontró en el
Resección de segmento medial del lóbulo derecho.

Primer tratamiento anti-TB: 2RHEZ 4R2H2. No negativiza.

Segundo tratamiento anti-TB: 2RHEZ 4R2H2. No negativiza.
Primer tratamiento antimicobacteria: claritromicina, etambutol, isoniacida y rifampicina, abandonando en la primera toma por intensa cefalea y tremor.
Segundo tratamiento antimicobacteria: azitromicina y moxifloxacina, y dos semanas después etambutol. Además: amitriptilina, omeprazol y cinitaprida, y tratamiento no farmacológico (cambio de estilo de vida). 8 meses después abandona tratamiento por mejoría de síntomas.

Tercer tratamiento antimicobacteria: azitromicina y moxifloxacina y etambutol. Además: amitriptilina, omeprazol y cinitaprida, y tratamiento no farmacológico (cambio de estilo de vida).

Fin de tratamiento. Se mantiene cambio de estilo de vida.

Figura 1. Flujograma con la descripción de las manifestaciones clínicas y el tratamiento recibido 
esputo bacilos ácido alcohol resistentes (BAAR) 2+, por lo que, recibió nuevamente el esquema $2 \mathrm{RHEZ}_{2} \mathrm{R}_{2} \mathrm{H}_{2}$ sin llegar a negativizar. Se consideró como posibilidad diagnóstica tuberculosis multidrogorresistente (MDR) (Figura 2D, 2E).

El 2013, en cuatro de los cultivos realizados por el Laboratorio de Referencia Nacional de Micobacterias (LRNM) del Instituto Nacional de Salud, se identificó Mycobacterium intracellulare. El 2014, la paciente recibe tratamiento con el esquema claritromicina, etambutol, isoniacida y rifampicina, sin embargo, lo abandonó en la primera toma por presentar intensa cefalea y tremor.

El 2015, la paciente volvió a consulta y recibió tratamiento con azitromicina, moxifloxacina y dos semanas después etambutol. El 2016, un médico psiquiatra le diagnosticó depresión, por lo que fue tratada con amitriptilina $(75 \mathrm{mg} /$ día). También recibió medicación por síntomas intensos de enfermedad por reflujo gastroesofágico (ERGE). Fue tratada con omeprazol (20 mg por día), cinitaprida (1 mg tres veces por día), además recibió tratamiento no farmacológico que consistió en la modificación de su estilo de vida (incluso una dieta estricta). Al tercer mes de tratamiento, sus tres pruebas de esputo fueron BAAR negativos. A los ocho meses de tratamiento la paciente dejó de presentar tos y abandonó el tratamiento.

De manera progresiva la tos empeoró y se hizo productiva. La paciente perdió $3 \mathrm{~kg}$ de peso. Después de 18 meses, presentó hemoptisis leve y una nueva prueba de esputo resultó BAAR positiva. La tomografía espiral multicorte (TEM) de tórax mostró lesiones compatibles con bronquiectasias y nódulos (Figura 2F y $3 \mathrm{~A}$ ).

El 2017, la paciente reinició el tratamiento por depresión, ERGE, y recibió el mismo esquema para Mycobacterium intracellulare. Al mes de tratamiento la adherencia a los tratamientos de las tres condiciones era absoluta. La paciente aumentó un kilogramo de peso, disminuyó la tos en frecuencia e intensidad y los síntomas depresivos desaparecieron. Presentó una erupción dérmica, por lo que, se le retiró la moxifloxacina. La erupción remitió, y se reemplazó la moxifloxacina por amikacina a $500 \mathrm{mg}$ por día por 50 dosis, para luego recibirla dos veces por semana.

$\mathrm{Al}$ cuarto mes del tratamiento, la paciente manifestó que durante el último mes había tenido un único episodio de tos, su peso había aumentado en tres kilogramos y la TEM de control mostró desaparición de signos de actividad de enfermedad pulmonar (Figura $2 \mathrm{G}$ y Figura 3B).

Al completar el año de tratamiento, la paciente estaba asintomática y había ganado seis kilogramos. Los exámenes de esputo fueron negativos, tanto los directos como los cultivos. La TEM de tórax mostraba desaparición de los signos de actividad de la enfermedad pulmonar por micobacterias no tuberculosas (EPMNT) (Figura 2H y Figura 3C). La paciente fue dada de alta en el 2018.

\section{DISCUSIÓN}

Presentamos un primer caso en el Perú de Mycobacterium intracellulare en una persona inmunocompetente, que previamente fue tratada por tuberculosis, pues se le hallaron granulomas en el segmento pulmonar resecado. Estos pacientes cuando son tratados con los regímenes usados en tuberculosis, presentan comúnmente recaídas, por la elevada resistencia a estos fármacos ${ }^{(3)}$. Cinco años después de haber sido dada de alta recibió por segunda vez el esquema $2 \mathrm{RHEZ4R}_{2} \mathrm{H}_{2}$, no negativizando y siendo declarada como un fracaso al tratamiento. A pesar de la indicación de ser tratada como tuberculosis multidrogorresistente, la terapia no inició por razones administrativas.

Las micobacterias no tuberculosas (MNT) se dividen en las de rápido crecimiento, cuando en cultivo crecen en dos semanas; y las de lento crecimiento, cuando lo hacen luego de cuatro semanas, tiempo semejante al del Mycobacterium tuberculosis. Dentro de las MNT de crecimiento lento está el Mycobacterium intracellulare, que forma parte del complejo MAC, cuyas colonias en los medios de cultivo sólidos tienen apariencia de tapiz fino, no cromógeno, con pequeños matices de transparencia, pero que al teñirlos con Ziehl-Neelsen son bacilos muy finos, de longitud irregular, más bien cortos, $\mathrm{y}$ aparecen sueltos, sin formar cordones ni agrupaciones, lo que permite diferenciarlos del M. tuberculosis ${ }^{(4)}$, y llevar a realizar la tipificación de la EPMNT.

Las MAC (Mycobacterium avium, Mycobacterium intracellulare y otras especies) se diagnostican por métodos de tipificación genética y biología molecular. En el Perú se usa el análisis de secuencias de ADN, donde se analizan las regiones llamadas A y $\mathrm{B}^{(5)}$. A diferencia de la $\mathrm{TB}$, donde un cultivo positivo suele ser suficiente para definir la enfermedad, para cumplir con los criterios de la American Thoracic Society / Infectious Diseases Society of America (ATS/IDSA) para EPMNT, un paciente debe tener síntomas característicos, radiología compatible y dos o más muestras de esputo cultivo positivo ${ }^{(2)}$. Estos criterios fueron cumplidos por nuestra paciente. Solo el $2 \%$ de los pacientes con un cultivo positivo tendrán progresión radiológica, mientras que si son dos o más cultivos positivos, el $98 \%$ progresará a enfermedad ${ }^{(6)}$. Se ha reportado que, el $14 \%$ de los pacientes con un solo cultivo de esputo positivo para MNT patógena, fueron diagnosticados como EPMNT durante el seguimiento, y la mayoría de estos pacientes tenían bronquiectasias sin lesiones cavitarias ${ }^{(7)}$.

La enfermedad bronquiectásica nodular por MAC se presenta con infiltrados nodulares e intersticiales que con frecuencia afectan el lóbulo medio, predominantemente en mujeres blancas posmenopáusicas, no fumadoras ${ }^{(8)}$, como nuestra paciente. Tiende a tener una progresión mucho más lenta que la otra forma que es la fibrocavitaria ${ }^{(9)}$. Siguiendo lo recomendado por la ATS/IDSA, la paciente recibió azitromicina, me- 


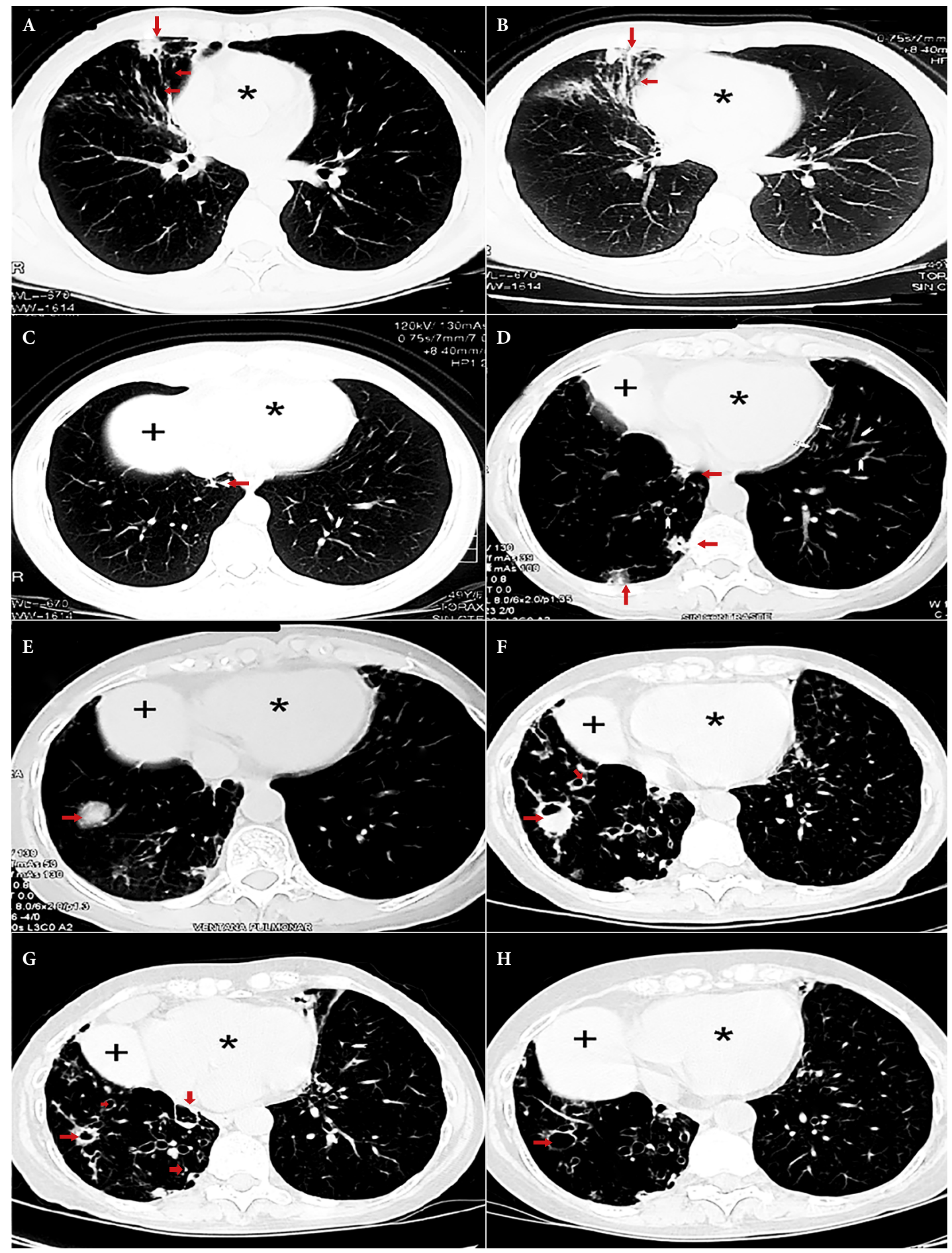

Figura 2. Tomografía espiral multicorte (TEM) de tórax, corte sagital del lóbulo medio, se observa el corazón (asterisco). A) Catorce años antes de salir de alta, pulmón derecho presenta lesión espiculada (flecha negra) con dos bronquios por fuera y uno por dentro cortados a través; y en la língula por fuera del corazón varios bronquios levemente dilatados (puntas de flecha blanca). B) Hay múltiples bronquiectasias cilíndricas (flecha blanca) y una lesión nodular densa inmediatamente por detrás de la pared anterior del tórax (flecha negra) C) Las bronquiectasias son cilíndricas y con su luz mayor que en A (flecha blanca). D) Diez años después de $\mathrm{C}$ la lesión espiculada (flecha blanca) ha aumentado levemente de tamaño y los bronquios que la rodean son de paredes más gruesas (puntas de flecha blanca) cuyo diámetro es más del doble que el de los vasos los acompañan. E) Un año y medio después de $\mathrm{D}$, las lesiones descritas en $\mathrm{B}$ persisten. F) Dos años después de $\mathrm{E}$. G) Cinco meses después de F, la lesión nodular es de menor tamaño. H) Siete meses después de G final del tratamiento, la lesión nodular es ahora una bula de menor tamaño (flecha blanca), los bronquios del pulmón derecho e izquierdo tienen paredes de menor grosos que en $\mathrm{G}$ y ninguna con nivel hidroaéreo 

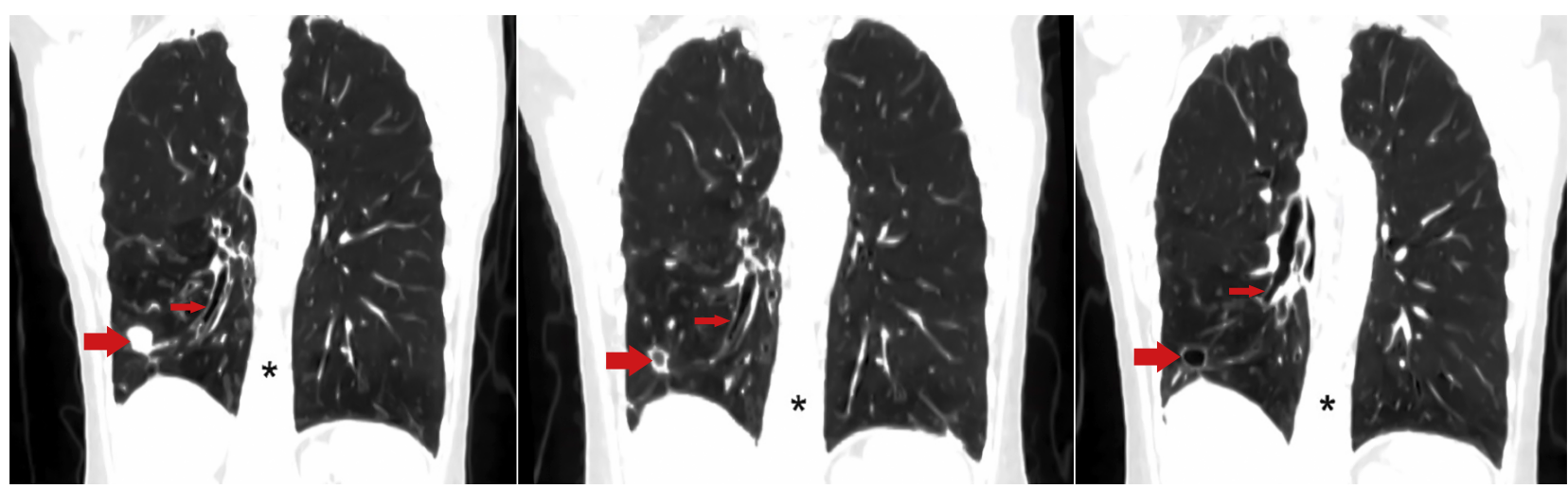

Figura 3. Tomografía espiral multicorte (TEM) de tórax, en cortes axiales. Se observa la columna vertebral (asterisco), bronquiectasias cilíndricas (flechas delgadas blancas) y un nódulo basal externo (flecha gruesa blanca) en el pulmón derecho. A) TEM antes del tratamiento final el nódulo es sólido $(18,1 \times 15,1 \mathrm{~mm})$ y el bronquio del lóbulo inferior es de paredes gruesas. B) TEM a los 5 meses del tratamiento el nódulo ha disminuido a 10,9 $\times 14,5 \mathrm{~mm}$ y se ha cavitado disminuyendo el grosor de las paredes del bronquio del lóbulo inferior. C) $\mathrm{Al}$ año de tratamiento el nódulo cavitado ha disminuido sus paredes observándose como una bula $(14,3 \times 12,1 \mathrm{~mm})$.

dicamento central para tratar a esta MNT, con moxifloxacina y etambutol ${ }^{(2)}$. Esta paciente tuvo primero síntomas respiratorios y luego bronquiectasias en el lóbulo medio derecho, sin otras lesiones en la base. El Mycobacterium intracellulare y/o el complejo MAC son más frecuentes en personas con lesiones preexistentes en el pulmón ${ }^{(3)}$. El tener ERGE pudo ser la causa de dichas lesiones ${ }^{(10)}$, las que por la orientación más vertical del bronquio derecho se localizan con mayor frecuencia en el pulmón derecho ${ }^{(11)}$. Uno de cada cuatro de los pacientes con EPMNT tiene ERGE y de ellos solo el 26\% tiene los síntomas típicos de ERGE, que son acidez estomacal y regurgitación ácida ${ }^{(10)}$. La ERGE está asociada a una variedad de enfermedades respiratorias como asma, EPOC, fibrosis pulmonar idiopática, e incrementa el riesgo de hacer TB en $63 \%{ }^{(12)}$.

En la depresión hay una reducción en el número y porcentaje de linfocitos y en la respuesta de las células $\mathrm{T}$ de memoria, lo que disminuye la inmunidad y predispone la enfermedad tuberculosa ${ }^{(13)}$. La depresión es el factor más importante y frecuente de abandono del tratamiento de la tuberculosis ${ }^{(14)}$. Por otro lado, se ha reportado que el tratamiento para la depresión con tricíclicos, podría mejorar la respuesta de los macrófagos ${ }^{(15)}$.

En conclusión, presentamos el primer caso en el Perú de una paciente inmunocompetente con antecedentes de tratamiento a tuberculosis y enfermedad bronquiectásica nodular por Mycobacterium intracellulare, además de depresión y ERGE, que logró curarse luego de varios años de tratamiento, mostrando al alta bronquiectasias sin signos de inflamación.

\section{Fuentes de financiamiento: Autofinanciado.}

Contribuciones de autoría: RAA y AC han participado en la concepción del artículo, la recolección de datos y la redacción del artículo. RAA aprobó la versión final.

Conflictos de interés: Los autores declaran no tener conflictos de interés en la publicación del artículo.

\section{REFERENCIAS BIBLIOGRÁFICAS}

1. Saito H, Tomioka H, Sato K, Tasaka H, Dawson DJ. Identification of various serovar strains of mycobacterium avium complex by using DNA probes specific for mycobacterium avium and mycobacterium intracellulare. J Clin Microbiol. 1990;28(8):1694-7.

2. Griffith DE, Aksamit T, Brown-Elliott BA, Catanzaro A, Daley C, Gordin F, et al. An official ATS/IDSA statement: diagnosis, treatment, and prevention of nontuberculous Mycobacterial Diseases. Am J Respir Crit Care Med. 2007;175(4):367-416. doi: 10.1164/rccm.200604-571ST.

3. Moran JF, Alexander LG, Stauh EW, Young WG, Sealy WC. Long-term results of pulmonary resection for atypical mycobacterial disease. Am Thorac Surg 1983;35(6):597-604.

4. Santos M, Gobernado M. Complejo Mycobacterium avium: Aspectos Microbiológicos [Internet]. Seimc.org. [citado 29 de octubre 2019]. Disponible en: https://seimc.org/contenidos/ccs/revisionestematicas/ micobacterias/macl.pdf.
5. Prevots DR, Marras TK. Epidemiology of human pulmonary infection with non-tuberculous mycobacteria: a review. Clin Chest Med. 2015;36(1):13-34. doi: 10.1016/j.ccm.2014.10.002.

6. Tsukamura M. Diagnosis of disease caused by Mycobacterium avium complex. Chest 1991;99(3):667-9. doi: 10.1378/chest.99.3.667.

7. Koh WJ, Chang B, Ko Y, Byeong-Ho J, Goohyeon H, Hye Yun P, et al. Clinical significance of a single isolation of pathogenic nontuberculous mycobacteria from sputum specimens. Diagn Microbiol Infect Dis 2013;75(2):225-6. doi: 10.1016/j.diagmicrobio.2012.09.021.

8. Huang JH, Kao PN, Adi V, Ruoss SJ. Mycobacterium avium-intracellulare pulmonary infection in HIV-negative patients without pre-existing lung disease: diagnostic and management limitations. Chest 1999;115(4):1033-1040. doi: 10.1378/chest.115.4.1033.

9. Kwon Y, Koh W, Daley C. Treatment of Mycobacterium avium Complex Pulmonary Disease. Tuberc Respir Dis (Seoul). 2019;82(1):15-26. doi: 10.4046/trd.2018.0060. 
10. Koh WJ, Lee JH, Kwon YS, Lee KS, Suh GY, Chung MP, et al. Prevalence of gastroesophageal reflux disease in patients with nontuberculous mycobacteria lung disease.Chest. 2007;131(6):1825-1830. doi: 10.1378/chest.06-2280.

11. Bakal Ü, Keleş E, Saraç M, Karlidağ T, Kaygusuz I, Kazez A. A Study of Foreign Body Aspiration in Children. J Craniofac Surg. 2016;27(4):e358-63. doi:10.1097/SCS.0000000000002582.

12. Fan WC, Ou SM, Feng JY, Hu YW, Yeh CM, Su VYF, et al. Increased risk of pulmonary tuberculosis in patients with gastroesophageal reflux disease. Int J Tuberc Lung Dis. 2016 ;20(2):265-70. doi: 10.5588/ ijtld.15.0251.
13. Zorrilla E P, Luborsky L, McKay J R, et al. The relationship of depression and stressors to immunological assays: a metaanalytic review. Brain Behav Immun. 2001;15:199-226

14. Ugarte-Gil C, Ruiz P, Zamudio C, Canaza L, Otero L, Kruger H, Seas C. Association of major depressive episode with negative outcomes of tuberculosis treatment. PLoS One. 2013;8(7):e69514. doi: 10.1371/ journal.pone.0069514.

15. Nazimek K, Strobel S, Bryniarski P, Kozlowski M, Filipczak-Bryniarska I, Bryniarski K. The role of macrophages in anti-inflammatory activity of antidepressant drugs. Immunobiology. 2017;222(6):823-30. doi: 10.1016/j. imbio.2016.07.001. 